\title{
What Is a Good Workplace? Tracing the Logics of NPM among Managers and Professionals in Swedish Elderly Care
}

\section{Britt-Inger Keisu'}

Senior lecturer, Department of Sociology, Umeå University, Umeå, Sweden

\section{Ann Öhman}

Professor, Umeå Centre for Gender Studies, Umeå University, Umeå, Sweden

\section{Birgit Enberg}

Senior Lecturer, Department of Community Medicine and Rehabilitation, Umeå University, Umeå, Sweden

\begin{abstract}
Neoliberal policies such as new public management (NPM) have been pivotal to the Swedish elderly care system for two decades. This article explores the discourses of NPM and work by focusing on how a good workplace is represented by professionals and managers in Swedish elderly care. Using qualitative interviews with 3 I managers, nurses, physiotherapists, and occupational therapists at nine workplaces, we identified four competing meanings ('storylines') of how a good workplace is constructed among the interviewees within an ongoing struggle between two discourses. Three storylines, i.e., striving to achieve the mission, a desire to work in elderly care, and striving for good working relationships, are linked to the neoliberal discourse of organizational effectiveness. In contrast, the fourth storyline, support and better working conditions, is related to a welfare-state discourse of traditional labor relations with strong historical roots. Four subject positions available to the managers and professionals were identified: the bureaucrat, the passionate, the professional, and the critic. We conclude that NPM is translated on top of existing discourses, such as those of traditional labor relations, care ideals, and practices, that are already established in elderly care workplaces and that counteract the new policy.
\end{abstract}

\section{KEY WORDS}

Elderly care / good workplace / manager / nurse / occupational therapist / physiotherapist / critical discourse psychology

DOI

10.19154/njwls.v6il.4884

\section{Introduction}

ew public management (NPM) has been pivotal to the Swedish elderly care system for approximately two decades (Kamp and Hvid 2012). NPM, which is characterized by its emphasis on managerialism and marketization, is arguably a necessary response to healthcare delivery problems such as efficiency and quality (Bergmark 2008;

\footnotetext{
${ }^{1}$ Corresponding author: britt-inger.keisu@umu.se
} 
Kamp and Hvid 2012). Among the most fundamental concerns of a welfare state is to provide high-quality care and rehabilitation for its ageing population. Still, care for elderly people follows various paths across societies. Some countries invest more than others, and different caring regimes are found even between welfare states (Anttonen and Sipilä 1996). In Sweden, elderly care is offered and available to all, regardless of socioeconomic status; it is considered generous, publicly financed elderly care of high quality. There are disagreements about the significance, distribution, and direction of neoliberal ideas in NPM in the public sector, including in elderly care (Dahl 2012; Pollitt 2002). As Dahl (2012: 283) puts it, however, consensus holds that 'neo-liberalism has been a transnational discourse that has recently changed public organizational cultures and redrawn the boundaries between the private and the public in various ways.' According to Dahl (2012), neoliberalism has been 'translated, mediated and adapted' in various national and local contexts. In Sweden and its Nordic context, the particular institutional context of the woman-friendly welfare state might, due to the prevalence of universalism and rule of law, constitute either an exceptional or a hostile environment for this trend (Dahl 2012: 284).

The dramatic changes undergone by elderly care are assumed to have disrupted and changed the culture as well as the professional ethos and identities in care work (Clarke and Newman 1997; Dahl 2012). However, principles previously applied in elderly care workplaces may have counteracted NPM principles or new developments may have arisen, running parallel to or entangled with NPM. Thus, both losses of meaning/identity and endeavors to construct new meaning/identity are possible (Kamp and Hvid 2012). Still, little is known about how neoliberalism and its ideology function in Nordic welfare regimes or at the workplace level in elderly care (Dahl 2012). Accordingly, this article explores the discourses of NPM and work in Swedish elderly care by focusing on how a good workplace is represented by professionals and managers. Elderly care is regarded as a relational field of work whose central components are said to be emotions and caring dispositions, such as empathy, communication abilities, common sense, problem-solving abilities, and ability to read people (Fejes 2012; Vabø 2006) - that is, caring about others and their needs (Skeggs 1997). The historical background of the elderly care sector is that it used to be informal; established in the 1950s, it was based on expected femininity, such as housewifely skills and virtues (Dahl 2000). These femalecoded traits and behaviors have long been part of the organizational culture and ideals of elderly care.

Many authors report that employees in elderly care experience time pressure, emotional pressure, work overload, stress, and loss of autonomy (Hayes et al. 2006; Josefsson 2012; Josefsson et al. 2007; Theobald and Szebehely 2013; Trydegård 2005). The rationale of effectiveness that NPM embraces may undermine the possibility of meeting elderly people's needs (Kamp 2012). Research finds that autonomy and the possibility of exercising care disposition are crucial-constituting core values-for doing satisfactory care work. The meaning of care work and the identity of care workers are therefore challenged by NPM rationales with its focus on efficiency. However, care work is also characterized by specific techniques and practical tasks, such as evidence-based practices, long emphasized as standard procedures and criteria for good-quality care and rehabilitation (Grol and Grimshaw 2003). This implies caring for others (Skeggs 1997). Accordingly, science-based knowledge is positioned as the most valuable and 'truest' knowledge in elderly care, superseding caring dispositions (Fejes 2012). A study 
of Swedish elderly care identifies a reconfiguration of how knowledge is valued in care work, caring dispositions and science-based knowledge appearing to be in transition toward a somewhat more equal positioning.

In the section 'NPM in elderly care' we review selected studies of NPM in elderly care and depict the aim and research questions of this study. In the following section, the theory of 'the logics of NPM' is explained and in 'Material and critical discursive psychology,' we describe our data and analytical approach. The section 'Findings and analysis' presents the empirical and theoretical analysis of representations of a good workplace. Finally, in 'Conflicting interests and subject positions,' we discuss the subject positions available to and employed by elderly care managers and professionals.

\section{NPM in elderly care}

Of particular interest here are the ways in which the neoliberal ideas embodied in NPM have influenced professional identity, workplace culture, and working conditions in care work. In a Norway-based study, Vabø (2006) scrutinizes 'consumerism' as the major driving force of Nordic welfare reforms. Vabø's analysis of the underlying assumptions of the past systems and current reforms of home-care services reveals that both 'time and attention are increasingly directed towards the formal procedures of proxy consumers, and less towards the well-being of people in need of care' (p. 419). However, even though care staff are subject to and disciplined through the discourse of consumerism, they still resist the system. The caring rationale is still a part of the culture, and staff base their actions on the belief that good care requires empathetic attention for greater emphasis to the frail elderly and their incapacity. Hence, they make tacit adjustments and conduct 'rescue operations' in their day-to-day practice when assisting the elderly. Paradoxically, this rearguard action may serve to deflect attention from moral dilemmas as the care workers act as 'invisible buffers' against negative outcomes, serving to sustain the dominant neoliberal discourse and system. Along the same lines, Rasmussen (2004) considers how public care work in Norway (as in other Nordic countries) has been decentralized into autonomous cooperative teams at the same time as power over resources is becoming centralized, further intensifying the work. The institutions are thus made greedy (for more about greed, see also Acker 1994).

A comparative study of long-term care reforms and their consequences for care workers in Sweden and Germany identifies country-specific adaptations of reform processes and their effects depending on the reforms' different initial conditions (Theobald and Szebehely 2013). Nevertheless, the reforms still affected care workers in both countries. There were indicators of precarious employment structures and that the working conditions of care workers had worsened, although to different extents. A Swedish local-level case study conducted by Sundin and Tillmar (2010) examined how customerchoice models in home-based elderly care have given rise to an ongoing process of gendering and regendering. One argument is that, in this woman-dominated sector, women's entrepreneurship is supported by these reforms, as are working conditions in the sector. The authors conclude that the unintended consequences are disappointing from the decision-makers' perspective, as elderly care sector reforms are labeled as embodying an increased masculinism that has masculinized the sector. In a conceptual paper, Hedegaard and Ahl (2013) conclude that NPM transformations have increased the 
systematic control of healthcare delivery at the expense of healthcare workers, because the performance improvements reproduce rather than challenge the gendered hierarchy. Clinical efficiency and customer satisfaction may be increased by multiprofessional collaboration, while dissatisfaction may also be increasing among professionals lower in the hierarchy as they are seen as less collaborative. Innovations in healthcare delivery may change the delivery of care, Hedegaard and Ahl (2013) explain, but this still might not challenge gender inequalities in healthcare; they propose 'that the stress on being collaborative and amenable to change prevents individuals from challenging current social orders' (p. 152).

In a study of home-help providers in Denmark, Dahl (2009) examines micropolitics and exposes how NPM has been translated in two municipalities. NPM is ambiguous and both the logic of detail (i.e., bureaucratic practices) and the logic of selfgovernance (i.e., improving care workers' qualifications), which are also considered here, are found in each municipality, although the relationship varies depending on the context. In one municipality, the logic of detail has dominated, creating a widespread feeling of misrecognition. Home-help providers have acted as invisible buffers (see Vabø 2006): by not bringing problems to their superiors' attention, they enabled the smooth functioning of NPM, reproducing NPM as the neoliberal logic of detail and as a neoliberal policy tool (Dahl 2009). In the other municipality, in contrast, the logic of self-governance has dominated and created recognition, i.e., a feeling of being seen and heard, among the home-help providers. However, Dahl concludes that the providers are not passive recipients of discourse; instead, they employ strategies of resistance as they negotiate with managers, the elderly, and coworkers and campaign for recognition of and visibility for their work.

The professionalization of management is one aim of NPM, and Rasmussen's (2012) study of managers in home-based care and nursing homes scrutinizes this change. In public services, managerial identity is based on the ethical values of the relevant profession (nurses often occupy managerial positions in healthcare) and on loyalty to the services provided, but there has been a shift toward a general management identity that rewards generic management skills. This marks a move away from a position in a professional hierarchy to an assumed empowered position in a managerial hierarchy. Rasmussen (2012) found that nursing home managers were able to meet the emphasized budget discipline demands, constructing themselves as powerful managers of elderly care. However, as managers of home-based care faced a more difficult situation and were unable to meet the budgetary demands, they could not draw on an NPM-empowered identity. Rather than being chief officers concentrating on the budget, another NPM logic was instead invoked as they concentrated on the professional discourse of delivering good-quality service for elderly people. Rasmussen (2012) argues that this discourse is in line with the traditional public ethos and the managers' professional identity as nurses.

Against this background the aim of this article is to explore the discourses of NPM and work in Swedish elderly care by focusing on how a good workplace is represented by professionals and managers. To illuminate potential tensions between the employer and employee perspectives, a qualitative study including first-level managers, nurses, physiotherapists, and occupational therapists was conducted at nine Swedish elderly care workplaces. The main research questions are: How is a good workplace represented as meaningful by the interviewees? How do interviewees use or resist the logics of NPM 
arising in an increasingly neoliberal setting? How are managerial and professional identities constructed?

\section{The logics of NPM}

Traditionally, socially liberal politics has taken account of the possibility and effect of tempering market forces through legal regulations and ethical principles. According to Wendy Brown (2003: 22), these values are today threatened by neoliberalism via a process in which almost all aspects of social life are submitted to economic calculation (Brown 2003: 22). Neoliberalism also brings with it the introduction of a new kind of governance and other technologies of control (Larner 2000). Hence, elderly care may be increasingly transformed by a neoliberal discourse of audit. One consequence of these shifts in politics from governance to governmentality is, according to Davies and Bansel (2010: 5), that "within neoliberal mentalities of government "welfare," or government responsibility for the well-being of the people, is constituted as a degraded mentality, and competitive market mentalities are elevated and given monolithic status.' This is assumed to systematically dismantle the desire to critique as it is through the market that both individuals and institutions are recognized. Against this backdrop, we therefore think that not only should neoliberalism be seen as an ideology or a policy, but that one should also analyze how it operates in terms of NPM.

Though definitions of the NPM concept differ (Pollitt 2002), this article emphasizes the two logics identified by other discourse studies of NPM: detail based on neoliberal economics originating in Taylorism (i.e., scientific management studies) and self-governance originating in human resource management (HRM) studies (see Dahl 2009: 635-638). These partially contradictory logics are held together by an overall idea of change. The logic of detail emphasizes rationalization, governed by the control of time, standardization, codification, and the division and governance of details. This logic disciplines care by splitting it up into, for example, standardized tasks and functions governed by detailed regulations, creating more hierarchical and bureaucratic practices (i.e., technologies of control, Larner 2000). In contrast, the logic of self-governance deemphasizes bureaucratic practices but instead stresses good leadership, self-governance, and cooperation (Dahl 2009). We believe that self-governance creates a foundation for decentralized power in care work that empowers care workers. Nevertheless, as Dahl (2009) points out, self-governance disciplines care workers in another way, providing challenges stemming from increased autonomy, learning, and training and obliging them to continuously improve their qualifications. We define power in line with Foucault's (1982) concept technologies of the self, as operating through direct ways of steering as well as through the production of free, responsible, and rational individual. The concept of governmentality captures thus both discursive process and individual doing, i.e., selfgovernance of the managers and professionals.

We therefore intend to trace these welfare state logics at various levels, from the national to the local-workplace levels, and to identify how these logics are used or resisted in storylines among the interviewed elderly care managers and professionals. These managers and professionals are positioned within the ongoing struggle between liberal welfare discourses of equal rights and neoliberal discourses. To capture the discourses of NPM and of work, we have asked about how a good workplace is constructed. 
Illustrating how these two discourses are employed at the workplace and discerning the existence of other discourses, as well as examining the construction of meaning and identity, are therefore the objectives of this article.

\section{Material and critical discursive psychology}

This study is based on 31 semi-structured interviews at nine workplaces in four Swedish regions. The interviews were conducted with 10 first-level managers (two men and eight women), four middle managers (one man and three women), and 17 employees in three occupations: five nurses, six physiotherapists, and six occupational therapists (three men and 14 women). In the following, participants who are members of these three professions will be referred to as 'professionals.' The workplaces were identified and selected from a prior questionnaire distributed in 2012 to professionals who were registered nurses, occupational therapists, or physiotherapists. The 1,024 respondents were asked to identify elderly care facilities that they regarded as well-functioning, which could serve as examples of good workplaces in elderly care. The workplaces consisted of eight public and one private elderly care institutions: four were nursing homes, two were rehabilitation centers for the elderly, and three were geriatric wards in hospitals.

In the interviews, the central questions asked of all managers and professionals addressed how they believed a good workplace was constituted. In addition, we discussed and asked several questions about the organizational prerequisites for achieving a good workplace, what hampers the creation of such a workplace, and whether wellbeing as a concept is part of the concept of a good workplace. In addition, we asked whether their workplaces conform to the vision represented. We also talked about the impact or priorities of their managers as well as the effects that the professionals themselves have in creating a good workplace.

The data were transcribed verbatim. Maxqda11 software was used to facilitate the qualitative analyses, using an analytical approach informed by critical discursive psychology (Edley 2001; Potter and Wetherell 1987; Wetherell 1998). As we are interested in how our interviewees speak and in how their identities are constructed, influenced, and reproduced via social interaction, critical discourse psychology was applied. From this perspective, mental processes are regarded as constituted through social, discursive activity rather than through individuals' internal processes. Potter and Wetherell (1987: 14) explain: 'We become less interested in what is going on under people's skulls and a lot more interested in how people are actually using language with each other in the course of different kinds of interactions.' We emphasize two central concepts in the analysis: interpretative repertoires, in this analysis called 'storylines,' and subject positions (Jones 2002: 6). The former are 'a family of related plots which carry with them recognisable characters, expected situations and anticipated outcomes.' These culturally available resources provide various ways of talking about a given phenomenon (Edley 2001). As NPM and work are addressed here, the storylines constitute the various ways the interviewees speak about and relate to the subject of interest through the lens of their representations of a good workplace. Therefore, we are not interested in differences among the interviewees depending on which of the nine workplaces they work at, but in how they speak about the phenomenon of interest. By means of structurally reading, organizing, and coding the text, various, and sometimes competing, storylines 
are constructed. The interviewees involved in elderly care can both draw on and resist various storylines, reproducing their own accounts. Still, not all storylines have the same status: some formulations are more available than others as they are more culturally dominant ways of understanding the world (Jones 2002). Critical discourse psychology can therefore capture the "paradoxical relationship that exists between discourse and the speaking subject. It acknowledges that people are, at the same time, both the product and the producers of discourse' (Edley 2001: 190). As the two groups, i.e., managers and professionals, are employers and employees, it is reasonable to assume that they have different perspectives, tasks, status, and power, which can produce differences in representation.

The second concept, subject positions, refers to the fact that, when the interviewees speak about a good workplace, they draw on various storylines in combination and to various extents, resulting in different subject positions. Subject positions are here defined as: 'locations within a conversation. They are the identities made relevant by specific ways of talking' (Edley 2001: 210). Within and between conversations, the way of talking can change, as can the identities of the speaker. How to identify a subject position is not straightforward, as it requires experience and intensive reading and rereading of the text. Being aware of 'who is implied by a particular discourse' or storyline is a useful technique that we have applied (Edley 2001: 210). We found various meanings of a good workplace emerging among the interviewed managers and professionals. After coding, reading, and rereading the data to distinguish patterns both within and between the two groups of personnel, two discourses emerged, i.e., a discourse of neoliberalism and a more complex discourse that we argue is interwoven with the Swedish labor relations tradition, the latter being characteristic of the Nordic model, with strong unions that frame working conditions as central to good work. The interviewees drew on two discourses, a neoliberal discourse of organizational effectiveness and a discourse of traditional labor relations. Within these discourses, connections between various storylines of a good workplace, including patterns of subject positions connected to these storylines, were formulated.

\section{Findings and analysis}

We found four ways of constructing representations of 'a good workplace' among the managers and professionals, i.e., four storylines. In the following, we describe and analyze each storyline. The storylines 'striving to achieve the mission' and 'a desire to work in elderly care' were concerned with what benefits the elderly care organization, whereas the third and fourth storylines, 'striving for good working relationships' and 'support and better working conditions,' originate from an employee perspective. Both physical and psychosocial well-being are deemed necessary if a workplace is to be considered a good one. The first two storylines were typically evident in interviews with managers, although the professionals' representations also employ these storylines, but to a limited extent. It was mainly the professionals who represented the third and fourth storylines.

Most interviewees said that they considered their workplace a 'good workplace' and many argued that what constitutes a good workplace in elderly care could be applicable to other types of workplace as well. However, some interviewees highlighted the specific context of elderly care with its logic based on a work ethics stemming from the fact that 
elderly people constitute a group of patients who are often both fragile and vulnerable, and that geriatric illness is complex to grasp.

\title{
Striving to achieve the mission
}

The managers' ideas about what characterizes a good workplace are clear, and their representations emphasize what benefits the elderly care organization. The professionals' representations also include this storyline, but to a very limited extent. The managers speak in two ways about this topic. Hence, this first storyline, striving to achieve the mission, means, according to one first-level manager: 'The task is at the centre. The task is always crucial, and what is important is our completing the task.' As another first-level manager put it, 'a good workplace mainly has the mission at the centre, the citizens, the patients.' In this storyline, many of the interviewees articulated the importance of monitoring and evaluating their work, as evident in the quotation below when a first-level manager was asked whether she considered her workplace 'a good workplace':

\begin{abstract}
Yes, I would probably say that this is a good workplace, based on what I see and on the level of care patients receive here, and the patient satisfaction, and the relatives' satisfaction, and the improvements that we see. My boss will certainly also mention to you the records that we keep here, the quality registers. There we can see very positive effects. And that is also evidence of this department being a good workplace. One of our main objectives is that patients should not return to the hospital. We monitor the re-hospitalization rate, for which we actually have the lowest numbers in the hospital-and this is satisfying and I am proud of it.
\end{abstract}

The interviewee similarly constructed a good workplace as meaningful with reference to patients' low rates of rehospitalization: 'this is satisfying and I am proud of it', she says. Another manager emphasized ISO guidelines for ensuring management system quality, in order to maintain a good workplace. As illustrated in another quotation, a first-level manager clearly highlighted the managers and management team as accountable for prioritizing the work:

There are clear expectations and it's clear what is included in the mission and it's clear where we're heading, what our goals are and what is considered important. What we prioritize in our business. So they [i.e., the professionals] have the clarity of knowing: 'Here we are on the road-this is our path and this is what we want to achieve.'

Like many other first-level managers, he also explained that the mandate must be clearly defined and that all individuals working in elderly care must regard the mission and organizational goal as important. As also illustrated by the above quotation, the interviewees often speak in terms of management by objectives when discussing what constitutes a good workplace.

The managers' representations in this storyline emphasize achieving the mission and what benefits the elderly care organization. They draw on a discourse of organizational effectiveness based on ideas of neoliberalism (Brown 2003) and in line with the principles of NPM (Vabø 2006). The managers' ethical values seem to be in transition toward a more general 
management identity (e.g., Rasmussen 2012). In this storyline, it is evident that achieving the mission, i.e., care of the elderly, occurs as an outcome of a well-functioning bureaucracy, of practices governed by the logic of detail (Dahl 2009). As Larner (2000) points out, technologies of control (e.g., ISO guidelines and other ways of monitoring and evaluating their work) are part and parcel of neoliberalism and managerialism. Accordingly, neoliberal discourses of audit are a dominant part of the elderly care culture, especially among managers (see Davies and Bansel 2010). Managers construct their identities by embracing the logic of NPM and are thus produced as accountable and responsible working subjects through these technologies (see, e.g., Rasmussen 2012).

\section{A desire to work in elderly care}

The second representation is a desire to work in elderly care, a storyline centering on what it takes to be a good employee in elderly care. According to the managers, professionals should have a desire and passion to work with elderly people. As with the first storyline, it is primarily the managers who construct the meaning of a good workplace in this way; professionals do use this storyline to some extent, though rarely.

A good workplace as characterized by the interviewees is a workplace where people want to work, as one first-level manager explained: 'I want to see an attitude that they think it's really great to work with the elderly. They shouldn't really want to be working in sports medicine.' The job must be regarded as 'amazing' and one should be in some way be 'passionate about this work,' another interviewee said. It is no good if individuals only work in elderly care due to a lack of alternatives, she continued. When discussing the differences between the phenomenon of a good workplace and well-being, an occupational therapist stated:

\footnotetext{
Nah, if you have a good and positive workplace you will likely also enjoy your work. If not, you simply have the wrong job that doesn't interest you at all—then it doesn't matter what workplace you have, if you don't think it's fun working as a nurse or if you're not interested.
}

In this storyline, constructed by many interviewees, representations of a good workplace center on enjoyment of work, defined as follows by a first-level manager: 'You go there, maybe not every day with joy, but most days with joy.' The first-level managers also believed that joyful professionals spread their positive energy to their coworkers whereas miserable people spread their negative energy. This was put in concrete terms when one first-level manager described the prerequisites for a good workplace. She is responsible for two departments, describing them as in total contrast to each other. In one department, employee turnover is high. The professionals at this department are convinced that they have excessive workloads compared to the other department. The manager explains that this is not the case; they complain and shout, despite receiving additional resources: maybe 'somewhere along the way, they have lost their job satisfaction,' she told us.

In discussing with one manager what he believed characterized a good workplace in elderly care, he said that if individuals are not 'passionate about caring for dying people,' they will not last long in palliative care, as illustrated in this quotation: 
Thus, in addition to management commitment, which I think is really important, I believe that one must be animated by the task somehow. And that is the big advantage of a palliative care unit-there is natural selection here, you could say. If you're not passionate about caring for dying people, then you won't stay in the palliative unit for very long. I won't say you have to quit the job-that's a harsh word—but you'll know yourself if it's wrong, you can't be bothered if that's the case. It becomes natural selection in that way.

The representation that 'one must be animated by the task' does not concern employee job satisfaction or professionals being joyful about their work. It embraces something deeper, which will be discussed later on. As in the above quotation, the interviewees' representations of elderly care reveal a workplace of elderly patients who have complicated multiple diagnoses, which produces heavy physical strain and a tough psychosocial workload for the professionals. Considerable patience is needed, and if one still enjoys working there, it is a good workplace, several first-level managers explained. One first-level manager said that sighing and complaining about the heavy workload often turns out to be self-defeating. She therefore wants professionals who can reflect on their own attitude to working with elderly people: that is 'the key to job satisfaction and the drive to work.' If professionals do not like their work tasks or the elderly people they work with, their coworkers can counterbalance their dissatisfaction and still experience a good workplace, another first-level manager said. One solution that the managers often mentioned is to end an employment contract in order to 'help people be what they want to be, and do a good job where they can do it and want to do it.'

In this storyline, a good workplace is constructed by the managers as an organization with professionals who enjoy and feel passionate about their work. As already mentioned, it is primarily the managers who construct meaning through this way of speaking. One manager said 'one must be animated by the task' and another said 'I want to have an attitude.' This type of representation does not concern a professional's job satisfaction, but rather emphasizes the importance of the professional's own desires. It embraces something deeper. We interpret these findings as representing a managerial view that working in elderly care is a 'calling.' It is not a type of behavior and knowledge constituting formalized competence, but rather tacit knowledge. Being emotionally committed and compassionate is culturally constructed as feminine and is associated with women's behavior (Hirdman 2001). It is constructed as a property of the professional's body and his or her mindset. If the work is not interesting to a professional, it would be better if he or she quit working in elderly care, the managers explain, and they will support the process of leaving the work.

Women dominate the elderly care sector, whose occupations are based on femalecoded traits and behavior. This reveals values historically embedded in the organizational culture, and the related representations recall the history of how these occupations were established (Dahl 2000). Nevertheless, the development of the professions of physiotherapist and occupational therapist can be distinguished from how the profession of nursing was established (see, e.g., Öhman 2001). For example, physiotherapy students currently attend to the competencies of both curing and caring in fairly similar ways (Dahl-Michelsen 2015), even though these competencies are historical and cultural constructions of doing femininity (i.e., caring) and doing masculinity (i.e., curing). However, we believe that the organizational culture in elderly care has primarily been influenced by the development of the nursing profession because registered and assistant 
nurses dominate the sector in numbers. In comparison, relatively few physiotherapists and occupational therapists are employed.

The notion of a 'calling' is a historically shaped concept that has influenced the development of the nursing profession (Andersson 2002). It expresses a particular professional ideal as well as an ethical attitude linked to the Christian heritage, i.e., the protestant work ethic characterized by strong altruistic features. The status and legitimacy of the nursing profession in society from the mid-1700s to the mid-1800s were strengthened by the nurses' proclamation of a calling. When the nursing profession was established in higher education, the notion of its being a calling was removed as an argument for choosing it as an occupation. In this study, only a few nurses, occupational therapists, and physiotherapists construct the meaning of a good workplace with reference to an occupational calling, although managers frequently did. The managers' invocation of calling reflects the organizational culture and its historical roots in the development of the nursing profession. One interpretation of this is that the difficulty of recruiting and retaining professionals within the organization, absent from managers' speech, is silently invoked by this talk of a calling. The concept of a calling has changed over time and, interestingly, still forms part of the ideal of the female care worker among the interviewed elderly care managers. If it is not possible for elderly care managers to offer high salaries and good career opportunities, at least they can offer an important job with high ethics. The firstlevel managers have few economic resources or career opportunities to offer to make the work more attractive to staff, so they appropriate and apply the cultural concepts available in the context.

In this storyline, as in the first storyline described, what benefits the organizational goal is represented as contributing to a good workplace. Professionals with the appropriate attitudes and a passionate desire to work in elderly care are supposed to be beneficial to the organizational culture. Managers construct their identities by embracing the NPM logic of empowering their professionals, as passionate individuals, to take responsibility for their elderly charges (Rasmussen 2012). The interviewed managers drew on a neoliberal discourse of organizational effectiveness (Vabø 2006). The managers' representations therefore exemplify normative workings of discourse. The neoliberal state governs in a subtle way, as though it could regulate the proper behavior and emotional responses of professionals, and the logic of self-governance becomes noticeable (see Dahl 2012: 286).

\section{Striving for good working relationships}

This third storyline dominates the professionals' representations of a good workplace. An illustrative quotation comes from a nurse: 'The worst-case scenario for me would have been to be alone or if I only had very few colleagues.' This interviewee talked about various prerequisites for a good workplace during the interview, putting professional relationships at work at the center. Work in elderly care is organized as teamwork, so collaboration is crucial, as illustrated in this quotation from an occupational therapist:

Good teamwork is essential. It has to be easy to collaborate, there has to be well-functioning cooperation between all the different professions, and the culture has to be unpretentious. The important thing is to reach the goal-that things will be good for the patientsand then it's not really important who does what, as long as you achieve that goal. 
In such cooperation it is important to be 'unpretentious' and to utilize all professionals' competences, this occupational therapist explained, because the goal of the organization is to provide good patient care. According to another professional, a heterogeneous work team, mixed in gender or age, is required for achieving a good workplace. A further prerequisite for well-functioning relationships between coworkers is that they support each other; one physiotherapist said that good working relationships 'should embody a good work ethic and everyone should feel that they are allowed to ask for help, and you shouldn't feel the need to be ashamed if you haven't had the time to finish your duties.' However, other types of support were also mentioned, such as consulting and giving each other positive and negative feedback and suggestions.

As also illustrated by the above quotation, professionals often emphasize coworkers' performance of their assigned tasks as meaningful when constructing a good workplace. This was also illustrated by an occupational therapist who explained: 'We have waiting lists. It may not be obvious the first week, if you're not doing your work, but then it becomes a problem and colleagues have to take responsibility for your tasks as well.' The professionals are closely interdependent and cohesive and sometimes, when the workload is heavy, they start laughing and keep laughing so hard that they eventually 'break down and cry.' There is good cooperation in a good workplace, one nurse said. Another aspect of interdependence is the rehabilitation perspective of the occupational therapists and physiotherapists. They are dependent on other groups of personnel, such as the assistant nurses, to take responsibility for the everyday work with the elderly that they introduce in their professional capacity. Interviewees also emphasized other aspects of the work ethic as prerequisites for a good workplace and good working relationships. These include, according to the interviewees, humanity and vibrant discussions about how to interact with each other, the elderly people, and their relatives. This also entails reaching agreement on what is appropriate care, and how to distribute it to the elderly people.

In this storyline, in which relationships are at the center of a good workplace, the working climate and organizational culture are also crucial; as one occupational therapist put it: 'It's important to have a good working climate among the staff because it is obvious to patients how we're doing, how we talk to each other, and if we're stressed.' Furthermore, it was said to be significant that colleagues be able to discuss a problem from various viewpoints while still respecting each other. One physiotherapist cited an example of the consequences of different cultures in the organization of elderly care:

Yes, but it also depends on the prevailing culture. For example, when individuals at risk of falling engage in active walking, there are cultural differences between workplaces. For example, in some places they want them [i.e., the elderly] belted into their seats if they have tripped even once, and elsewhere they say, 'Yes, of course, they must have the chance to walk around most of the time. Even though we want to prevent injuries, and we know that accidents could happen, we still want them to have a high quality of life, we want them to be active.' I have often wondered why there are such different cultures?

The organizational culture is important for the quality of care given to elderly people, but also for employee job satisfaction and well-being, as professionals represented during the interviews.

In this storyline, a good workplace is constructed as meaningful by the professionals, whose representations refer to good working relationships. They said it was 
important to be 'unpretentious' and 'collaborative,' to have 'a good work ethic,' and to create 'a good working climate' and well-functioning 'cooperation.' As elderly care work is based on autonomous work teams with extensive cooperation, a high degree of cohesion and interdependency emerges. Because of the organizational design of elderly care work, it is unsurprising that good working relationships are central to the meaning of a good workplace. Historically, the construction of femininity has been interwoven with relationship-oriented characteristics such as supporting, caring, and being emotionally involved in others' needs, putting one's own aside (Hirdman 2001; Skeggs 1997). The construction of femininity and what is represented as a good workplace thus coincide with the core value in care work, i.e., a caring disposition (Fejes 2012). Perhaps clinical efficiency has been increased through such multiprofessional cooperation, as Hedegaard and Ahl (2013) note, but it may also increase dissatisfaction because the stress of being collaborative arguably prevents individuals from challenging the current social order. Professionals' representations may strengthen and reproduce the social order of cohesion and dependence. This may clash with how the professionals were trained, that is, among other tasks, to independently investigate, evaluate, and coach others in (rehabilitative) work with patients (e.g., Dahl-Michelsen 2015; Öhman 2001). Another downside to the pattern of collective working is when cultural norms demand that individuals act in certain ways that they would not have chosen if the pressure to which they are exposed were to vanish (Lindgren 1985; Lysgaard 1961).

We argue that whether or not this organizational design of autonomous cooperative teams is beneficial for the professionals is related to the opportunities they have to maintain and develop skills within their professions. In our study, professionals report that creating good and healthy working relationships is problematic in elderly care because of the heavy workload. Another aspect related to the development of good working relationships is the unimportance of hierarchy that was stressed during the interviews. For example, one professional said: 'It's not really important who does what.' Simultaneously, conflicts and tensions were not explicitly constructed in the professionals' speech, though we believe that they are certainly also part of their everyday work. Organization into autonomous cooperative teams does not mean that power relationships are absent, but that they are reproduced in another form, allowing latitude for informal patterns of power (e.g., Acker 2006). However, judging from how the professionals spoke about their daily work, it seems as though their practices were informed by their professional identities as nurses, occupational therapists, and physiotherapists, creating a basis for their professional identities (i.e., Öhman 2001). Like the managers, who drew on a discourse of organizational effectiveness, the professionals' representations likewise recalled NPM, via the logic of self-governance carried out in the practices of team organization (Dahl 2009). The professional is produced as an accountable and responsible working subject through the self-governance discipline of proper behavior. When fulfilled, this creates the norms and ideal of a hard-working, independent but still collaborative coworker who contributes to the working climate with good work ethics.

\section{Support and better working conditions}

The fourth storyline, support and better working conditions, is part of how professionals construct and attribute meaning to the phenomenon. The interviewees described a 
stressful work situation having negative effects at various levels. The stress affects the care of the elderly as well as the professionals' job satisfaction and relationships at work. One physiotherapist said: 'If you really have a lot to do, there's no time to thrive together that much, you could say. You don't even have time to talk during coffee breaks.' In such a situation, the workplace cannot be considered a good one. A heavy workload means that 'everyone gets a little grumpy' and going to work is no longer fun, she added.

One important aspect of the workload is how the work is organized, and one professional highlighted the significance of having fewer people in the caring team in order to have good cooperation. Another mentioned that there have been too many structural changes in the organization, creating uncertainty and stress. When one occupational therapist was asked what characterizes a good workplace she stated: 'There's time for each individual patient and you have autonomy and are able to manage the work on your own. You shouldn't need too much help, but you should get help when it's needed.' A negative outcome of a heavy workload represented by one physiotherapist is illustrated in the quotation below, in which she describes her dream scenario:

In my dream scenario, there are more financial resources and you can do better work with each care resident. Today the work is fragmented and temporary. We would then be able to work proactively to a much greater extent, especially in preventing the elderly from falling. But there's no time for it. We thus could increase our home visits, perhaps inform the elderly and change their lining environment for them. We can't influence the medical issues, such as older people's balance, but if additional resources were available, nurses and other professionals could get more of a comprehensive picture of the patient and thus help to prevent falls.

In this storyline, having enough time to do the work is represented as crucial for creating a good workplace. Sufficient time is required for every step so that care can be well administered. The professionals' representations of a good workplace refer largely to negative experiences of changes in elderly care. An excessive focus on budgeting has been standard, and the number of positions has been reduced, leading to a shortage of personnel. Moreover, as one interviewee explained, 'the administration and documentation has increased since I started as an occupational therapist. Back then, the documentation was handwritten in paper journals.' To create a good workplace in elderly care, more resources are needed, one nurse explained. In addition, a heavy workload requires supportive managers and, in this storyline, first-level managers are pivotal to how the professionals attribute meaning to a good workplace. One physiotherapist summarized this as follows, exemplifying what several other professionals' constructions of a good workplace also represented:

It's important to be seen and praised and to have work autonomy as well as responsibility. That is a good way of working. The managers must trust their employees and not have the need to control everything. A manager should be the same as everyone else in the group and ought to be personal but not private. The professionals should not be afraid of having a conversation with the manager. The manager instills confidence and is perceptive of the employees' needs and not afraid to sort out problems. The manager is flexible and must be able to give and take criticism in an appropriate way. A manager should not impose any unnecessary formalities or red tape but be capable of thinking outside the box. 
There is a long list of the characteristics of a good manager, but several characteristics were represented as most important in creating a good workplace by this professional. A good manager must be enthusiastic, clear in showing the way forward, effective in uniting the work team by offering daily guidance, and available and present in the organization. In addition, a manager ought to be brave, orderly, a role model, and someone who solves emerging problems and communicates the professionals' interests and demands higher in the organizational hierarchy.

In this storyline, the professionals constructed a good workplace as meaningful by highlighting problems in their own workplaces. Heavy workloads and changes in elderly care affect job satisfaction (e.g., Theobald and Szebehely 2013). Rasmussen (2004) argues that this could hinder employees from having an 'authentic care relationship' (p. 17) with elderly people. In addition, the development of professional work relationships is also restricted. Working as a professional nurse, physiotherapist, or occupational therapist has therefore become a narrowed experience. The analysis reveals that the NPM logics of detail and self-governance are not present in this storyline, as NPM does not regulate proper behavior or emotional responses through these representations (see Dahl 2012). The professionals resist the transformational trends of NPM in elderly care as they draw on a welfare state discourse of traditional labor relations. The background to this is the Swedish labor relations tradition, characteristic of the Nordic model, in which strong unions bargain for healthy working conditions, achieving good working conditions. In the Swedish context, there is close collaboration between the Swedish Trade Union Organization (LO) and the Confederation of Swedish Enterprise (SN). The well-known Saltsjöbadsavtalet labor market agreement, signed in 1938, allows employees and employers to negotiate collective agreements and resolve disputes arising in the labor market, with the state playing a passive role (Andersson et al. 2006; Schmidt and Adlercreutz 1966). Although the Nordic model is in transition (Kettunen 2012), its historically embedded norms still influence workplace relations and regulations, noticeably when professionals emphasize issues relating to their working environment. Responsibility for occupational health and safety is usually delegated to first-level managers in elderly care, but collaboration with employees and/or union representatives is required (AFS 2001). Perhaps this historically embedded relationship has been affected by NPM because of its emphasis on economic efficiency. Nevertheless, the analysis reveals that this tradition has had a central impact on how a good workplace is constituted. In the storylines represented by the professionals, they construct their professional identities and ethos by co-opting the discourse of traditional labor relations.

We do not interpret the professionals' criticism of the NPM rationality as indicating a 'lack of meaning' (see Kamp 2012: 62). Rather, we believe that the professionals construct the meaning of work through established labor relations, assuming that their statements will be noticed and addressed. First-level managers with good skills are represented in this storyline as key actors in achieving a good workplace. However, these managers, situated in the lowest hierarchical leadership position, characterized by contradictory interests and demands, have a difficult task (Keisu 2009; Wolmesjö 2005). Their economic resources are restricted, so their opportunities to ease the professionals' workloads are limited (e.g., Rasmussen 2012). The power and authority to structurally transform elderly care is not in their hands. They function at the operational level, where they are required to implement uncomfortable decisions (decided higher in the organizational hierarchy) and to complete changes that have already been initiated. 
Consequently, this makes first-level managers paradoxically even more important as supports and buffers against negative outcomes in the working environment. In addition, the first-level managers studied here are each responsible for an average of 40 permanent employees as well as a large number of temporary staff, so their workloads are heavy as well.

\section{Conflicting interests and subject positions}

In our analysis, we identified four competing meanings ('storylines') of how a good workplace is constructed among the interviewed managers and professionals. It became clear that the interviewees are positioned within an ongoing struggle between discourses both upholding and rejecting the principles of NPM. The analysis revealed that managers differed from professionals in that their representations were exclusively located in the first and second storylines (see Table 1). The professionals' representations also employ these storylines, but only to a limited extent. The professionals' representations are primarily linked to the third and fourth storylines. Three storylines, i.e., striving to achieve the mission, a desire to work in elderly care, and striving for good working relationships, are linked to the neoliberal discourse of organizational effectiveness and are in line with the principles of NPM. Besides the economic aspects of the effective organization, better-quality care is another aspect of these three storylines. The fourth storyline, i.e., support and better working conditions, in contrast is related to a welfarestate discourse of traditional labor relations with strong historical roots. This storyline refers solely to the professionals' working conditions. Within these discourses, connections between the four storylines, including patterns of four related subject positions, are revealed. Four subject positions available to the managers and professionals were identified: the bureaucrat, the passionate, the professional, and the critic.

The bureaucrat, the first subject position, refers to an abstract figure stressing the importance of an effective and well-functioning bureaucracy in achieving a good workplace. She (or he) employs strategies designed to achieve the mission and goal, benefiting elderly care as an organization. This subject position reproduces NPM as the neoliberal logic of detail (based on neoliberal economics that originate in Taylorism, see Dahl 2012) and utilizes its policy tools to produce accountable and responsible working subjects. The passionate is the second subject position, which typically refers to an abstract figure who emphasizes the importance of professionals with attitudes appropriate for a good workplace. She (or he) employs strategies to recruit passionate professionals who feel joy about their work in elderly care, recalling the historical concept of a calling. Factors that benefit the organization are central to this subject position, which reproduces NPM practices governed by the logic of self-governance (originating in HRM research, see Dahl 2012) and disciplines and regulates individual emotional responses and behavior. The professional is the third subject position, referring to an abstract figure who puts professional working relationships at the center of a good workplace in elderly care. She (or he) employs strategies for developing cooperation, support, a good working climate, and a high standard of work ethics. This is a subject position that reproduces the logic of self-governance and regulates both the behavior and emotions of individuals working in elderly care. The critic is the fourth subject position, referring to an abstract figure concerned with the work environment in elderly care. The strategies of this subject

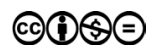


Table I The storylines represented by the interviewees together with the available subject positions and discourses employed

\begin{tabular}{lllll}
\hline & $\begin{array}{l}\text { Managers' } \\
\text { representation }\end{array}$ & $\begin{array}{l}\text { Professionals' } \\
\text { representation }\end{array}$ & $\begin{array}{l}\text { Subject } \\
\text { position }\end{array}$ & Discourse \\
\hline $\begin{array}{l}\text { I) striving to } \\
\text { achieve the } \\
\text { mission }\end{array}$ & high extent & limited extent & the bureaucrat & $\begin{array}{l}\text { neoliberal discourse } \\
\text { of organizational } \\
\text { effectiveness }\end{array}$ \\
\hline $\begin{array}{l}\text { 2) a desire to work } \\
\text { in elderly care }\end{array}$ & high extent & limited extent & the passionate & $\begin{array}{l}\text { neoliberal discourse } \\
\text { of organizational } \\
\text { effectiveness }\end{array}$ \\
\hline $\begin{array}{l}\text { 3) striving for good } \\
\text { working relation- } \\
\text { ships }\end{array}$ & absent from & high extent & the professional & $\begin{array}{l}\text { neoliberal discourse } \\
\text { of organizational } \\
\text { effectiveness }\end{array}$ \\
\hline $\begin{array}{l}\text { 4) support and } \\
\text { better working } \\
\text { conditions }\end{array}$ & $\begin{array}{l}\text { absent from } \\
\text { representations }\end{array}$ & high extent & the critic & $\begin{array}{l}\text { discourse of traditional } \\
\text { labor relations }\end{array}$ \\
\hline
\end{tabular}

position include criticizing the heavy workload and its consequences for elderly people as well as making an issue of care quality and the (women) professionals' job satisfaction. This subject position does not use the logic of NPM but instead resists and protests the transformations that elderly care is undergoing. She (or he) practices strategies for achieving decent prerequisites at work and manager support. It is a position that challenges and attempts to minimize the negative impacts that the NPM logics of detail and self-governance have on work and care by upholding traditional ideas of labor relations and regulations and their influence on developing a healthy workplace environment.

Our analysis has traced the logic of NPM from the national level to the workplace, in individual application or resistance among elderly care managers and professionals, when exploring how NPM and work are constructed through the lens of how a good workplace is represented. We found that translations of NPM into elderly care differed between the managers' and professionals' representations. How the neoliberal ideas of NPM influenced the interviewees' identities and the workplace culture were revealed in our analysis. Managers construct their identities by embracing the logic of NPM. In contrast, the basis of the identities of occupational therapists, registered nurses, and physiotherapists primarily lies in their professional practices. Their representations recall the caring dispositions that constitute a core value in care work (Fejes 2012; Skeggs 1997). Hence, professionals, like managers, embrace NPM while carrying out the practices of team organization. Professionals' representations are ambiguous as they also resist the changes initiated by NPM by criticizing their negative consequences observable in the working environment-the professionals are not merely passive recipients of NPM. We conclude that NPM is translated on top of existing discourses, such as those of traditional labor relations, care ideals, and practices, that are already established in elderly care workplaces and that counteract the new management ideas. Different ways of relating to a good workplace, both at a conceptual level and in practice, lead to different consequences. From our study, we also conclude that elderly care managers and 
professionals have conflicting interests, emphasizing different organizational aspects of elderly care in constructing what constitutes a good workplace. Nevertheless, these parties are held together by the overall principle of providing good-quality care for elderly people.

\section{Acknowledgment}

We thank the informants in this project, who so generously shared their experiences and views on elderly care in Sweden. The project was financed by Forte; Swedish Research Council for Health, Working Life and Welfare; dnr. 2011-1140.

\section{References}

Acker, S. (1994) Gendered Education-Sociological Reflection on Women, Teaching and Feminism. Toronto: Open University Press. ISBN: 0-335-19059-6.

Acker, J. (2006) 'Inequality regimes: gender, class and race in organizations,' Gender \& Society, 20(4): 441-464. doi: http://dx.doi.org/10.1177/0891243206289499.

AFS (2001) Systematic Work Environment Management [Swedish Codes of Statutes]. 2001:01.

Andersson, A., Edström, Ö. and Zanderin, L. (2006). Arbetsrätt. [Labor Legislation]. Malmö: Liber. ISBN: 978-91-47-11100-8.

Andersson, Å. (2002) Ett högt och ädelt kall : kalltankens betydelse för sjuksköterskeyrkets formering 1850-1933 [A high and noble calling: The notion of a calling and the formation of the nursing profession]. Diss., Umeå Universitet. ISBN: 91-7305-180-2.

Anttonen, A. and Sipilä, J. (1996) ‘Social care services: Is it possible to identify models?' Journal of EuropeanSocialPolicy,6(2):87-100.doi: http://dx.doi.org/10.1177/095892879600600201.

Bergmark, Å. (2008) 'Market reforms in Swedish health care: normative reorientation and welfare state sustainability,' Journal of Medicine and Philosophy, 33(3): 241-261. doi: http://dx.doi.org/10.1093/jmp/jhn010.

Brown, W. (2003) 'Neo-liberalism and the end of liberal democracy', Theory \& Event, 7(1).

Clarke, J. and Newman, J. (1997) The Managerial State: power, politics and ideology in the remaking of social welfare. London: Sage. ISBN: 0-8039-7612-7.

Dahl, H.M. (2000) Fra kitler till eget tøj-diskurer om professionalism omsorg og køn [From smocks to one's own clothes-Discourses on profession, care and gender]. Diss., Aarhus: Politica. ISBN: 87-7335-097-4.

Dahl, H.M. (2009) 'New public management, care and struggles about recognition,' Critical Social Policy, 29(4): 634-654. doi: http://dx.doi.org/10.1177/0261018309341903.

Dahl, H.M. (2012) 'Neo-liberalism meets the Nordic welfare state: gaps and silences,' NORA: Nordic Journal of Feminist and Gender Research, 20(4): 283-288. doi: http://dx.doi.org/ 10.1080/08038740.2012.747790.

Dahl-Michelsen, T. (2015) 'Curing and caring competences in the skills training of physiotherapy students,' Physiotherapy Theory and Practice, 31(1): 8-16. doi: http://dx.doi.org/10.3109/09593985.2014.949946.

Davies, B. and Bansel, P. (2010) 'Governmentality and academic work: shaping the hearts and minds of academic workers,' Journal of Curriculum Theorizing, 26(3): 5-20. ISSN: 1942-2563.

Edley, N. (2001) Analysing masculinity: interpretative repertoires, ideological dilemmas and subject positions, pp. 189-228. In Wetherell, M., Taylor, S. and Yates, S.J. (eds) Discourse as Data: A Guide for Analysis. London: Sage. ISSN: 0018-7267. 
Fejes, A. (2012) Knowledge at play: positioning care workers as professionals through scientific rationality and caring dispositions, pp. 83-105. In Kamp, A. and Hvid, H. (eds) Elderly Care in Transition: Management, Meaning and Identity at Work. A Scandinavian Perspective. Copenhagen: Copenhagen Business School Press. ISBN: 978-87-630-0244-8

Foucault, M. (1982) 'The subject and power', Critical Inquiry, 8(4): 777-795. doi: http://dx.doi.org/10.1086/448181.

Grol, R. and Grimshaw, J. (2003) 'From best evidence to best practice: effective implementation of change in patients' care', The Lancet, 362(9391): 1225-1230. doi: http://dx.doi. org/10.1016/S0140-6736(03)14546-1.

Hayes, L., O’Brien-Pallas, L., Duffield, C., Shamian, J., Buchan, J., Hughes, F., Spence L., Heather K., North, N., \& Stone, P. (2006). 'Nurse turnover: A literature review,' International Journal of Nursing Studies, 43: 237-263. doi: http://dx.doi.org/10.1016/j.ijnurstu.2005.02.007.

Hedegaard, J. and Ahl, H. (2013) 'The gender subtext of new public management-based work practices in Swedish health care,' Equality, Diversity and Inclusion: An International Journal, 32(2): 144-156. doi: http://dx.doi.org/10.1108/02610151311324389.

Hirdman, Y. (2001) Genus—om de stabilas föränderliga former [Gender-On the Changeable Form of Stability]. Malmö: Liber. ISBN: 91-47-07294-6.

Jones, R. (2002). 'That's very rude, I shouldn't be telling you that': older women talking about sex, Narrative Inquiry, 12(1): 121-142. doi: http://dx.doi.org/10.1075/ni.12.1.18jon.

Josefsson, K. (2012). 'Registered nurses' health in community elderly care in Sweden,' International Nursing Review, 59: 409-415. doi: http://dx.doi.org/10.1111/j.14667657.2012.00984.x.

Josefsson, K., Sonde, L., Winblad, B., Robins., \& Wahlin, T. (2007). 'Work situation of registered nurses in municipal elderly care in Sweden: a questionnaire survey' International Journal of Nursing Studies, 44: 71-82. doi: http://dx.doi.org/10.1016/j.ijnurstu.2005.10.014.

Kamp, A. (2012) Meaning of work in elderly care in Denmark: fragile reconstructions, pp. 107-132. In Kamp, A. and Hvid, H. (eds) Elderly Care in Transition: Management, Meaning and Identity at Work. A Scandinavian Perspective. Copenhagen: Copenhagen Business School Press. ISBN: 978-87-630-0244-8.

Kamp, A. and Hvid, H. (2012) Elderly Care in Transition: Management, Meaning and Identity at Work. A Scandinavian Perspective. Copenhagen: Copenhagen Business School Press. ISBN: 978-87-630-0244-8.

Keisu B. (2009) Att peka med hela handen. Om arbetsvillkor och kön bland första linjens chefer. [Wearing the pants: Working conditions and gender among first-level managers]. Diss., Umeå: Umeå University. ISBN: 978-91-7264-842-5.

Kettunen, P. (2012) 'Reinterpreting the historicity of the Nordic model,' Nordic Journal of Working Life Studies, 2(4): 21-43.

Larner, W. (2000) 'Neo-liberalism, policy, ideology, governmentality' Studies in Political Economy, 63: 5-25. ISSN 1918-7033.

Lindgren, G. (1985) Kamrater, kollegor och kvinnor-en studie av könssegregeringsprocessen $i$ två mansdominerade organisationer [Companion, colleagues and women - a study of the gender segregation process within two male-dominated organizations]. Diss., Umeå: Umeå University. ISSN 0566-7518.

Lysgaard, S. (1961) Arbeiderkollektivet [Worker collective]. Oslo: Universitetsforlaget (nytryck 1981). ISBN: 82-15-00002-9.

Öhman, A. (2001) Profession on the move: changing conditions and gendered development in physiotherapy. Diss., Umeå: Umeå University. ISBN: 91-7305-017-2.

Pollitt, C. (2002) 'Clarifying convergence: striking similarities and durable differences in public management reform,' Public Management Review, 4(1): 471-492. doi: http://dx.doi. org/10.1080/14616670110071847. 
Potter, J. \& Wetherell, M. (1987) Discourse and Social Psychology: Beyond Attitudes and Behaviour. London: SAGE Publications. doi: http://dx.doi.org/10.1111/j.2044-8309.1988. tb00818.x.

Rasmussen, B. (2004) 'Between endless needs and limited resources: the gendered construction of a greedy organization,' Gender, Work and Organization, 11(5): 506-525. doi: http://dx.doi.org/10.1111/j.1468-0432.2004.00245.x.

Rasmussen, B. (2012) New Public Management: constructing a new management identity in care for the elderly, pp. 165-186. In Kamp, A. and Hvid, H. (eds) Elderly Care in Transition: Management, Meaning and Identity at Work. A Scandinavian Perspective. Denmark: Copenhagen Business School Press. ISBN: 978-87-630-0244-8.

Schmidt, F. and Adlercreutz, A. (1966) Kollektiv arbetsrätt [Collective labor legislation]. Stockholm: Norstedt.

Skeggs, B. (1997) The Formation of Class and Gender. London: SAGE Publications. ISBN: 0-7619-5512-7.

Sundin, E. and Tillmar, M. (2010) 'Masculinisation of the public sector: local level studies of public sector outsourcing in elder care,' International Journal of Gender and Entrepreneurship: 2(1): 49-67. doi: http://dx.doi.org/10.1108/17566261011026547.

Theobald, H. and Szebehely, M. (2013) Care Workers and New Public Management: A Comparison of Long-Term Care Reforms and Their Effects on Care Workers in Sweden and Germany, Paper presented at the $11^{\text {th }}$ Annual ESPAnet conference, Poznan University of Economics, Poznan, Poland, September, 5-7, 2013 (Referencing is approved by the authors 20150329).

Trydegård, G. (2005) 'Äldreomsorgspersonalens arbetsvillkor I Norden-en forskningsöversikt' [The working conditions of home care workers in the Nordic countries-a review], 143-190. In Scebehely, M. (ed.) Äldreomsorgsforskning i Norden. En kunskapsöversikt [Elderly Care Research in the Nordic Countries. A Review]. TemaNord 2005:208. Copenhagen: Nordic Council of Ministers. ISBN 92-893-1120-7

Vabø, M. (2006) 'Caring for people or caring for proxy consumers?' European Societies, 8(3): 403-422. doi: http://dx.doi.org/10.1080/14616690600821990.

Wetherell, M. (1998) 'Positioning and interpretative repertoires: conversation analysis and post-structuralism in dialogue,' Discourse \& Society, 9(3): 387-412. doi: http://dx.doi.org/10.1177/0957926598009003005.

Wolmesjö, M. (2005). Ledningsfunktion i omvandling. Om förändringar av yrkesrollen för första linjens chefer inom den kommunala äldre- och handikappomsorgen [Management function in transformation: on the changes of occupational role for first-line managers within municipal elderly and disabled care]. Diss., Lund: Lunds Universitet. ISBN: 91-89604-28-8 